Research article

\title{
Identifying patient preferences for communicating risk estimates: A descriptive pilot study Jennifer M Fortin ${ }^{1}$, Linda K Hirota ${ }^{2}$, Barbara E Bond ${ }^{3}$, Annette M O'Connor ${ }^{4}$ and Nananda F Col ${ }^{* 1}$
}

Address: ${ }^{1}$ Decision Systems Group, Brigham and Women's Hospital, Harvard Medical School, Boston, Massachusetts, US, ${ }^{2}$ Graduate School for Health Studies/Nursing, Simmons College, Boston, Massachusetts, US, ${ }^{3}$ Department of Social Work, New England Medical Center, Boston, Massachusetts, US and ${ }^{4}$ Faculty of Health Sciences, University of Ottawa, Ottawa, Canada

E-mail: Jennifer M Fortin - fortin@dsg.harvard.edu; Linda K Hirota - lhirota@alumni.tufts.edu; Barbara E Bond - bbond@lifespan.org; Annette M O'Connor - aoconnor@lei.ca; Nananda F Col* - ncol@dsg.harvard.edu

*Corresponding author

Published: I August 200 I

Received: 5 May 2001

BMC Medical Informatics and Decision Making 200I, I:2

Accepted: I August 200I

This article is available from: http://www.biomedcentral.com/1472-6947/I/2

(c) 200I Fortin et al; licensee BioMed Central Ltd. Verbatim copying and redistribution of this article are permitted in any medium for any non-commercial purpose, provided this notice is preserved along with the article's original URL. For commercial use, contact info@biomedcentral.com

\begin{abstract}
Background: Patients increasingly seek more active involvement in health care decisions, but little is known about how to communicate complex risk information to patients. The objective of this study was to elicit patient preferences for the presentation and framing of complex risk information.
\end{abstract}

Method: To accomplish this, eight focus group discussions and 15 one-on-one interviews were conducted, where women were presented with risk data in a variety of different graphical formats, metrics, and time horizons. Risk data were based on a hypothetical woman's risk for coronary heart disease, hip fracture, and breast cancer, with and without hormone replacement therapy. Participants' preferences were assessed using likert scales, ranking, and abstractions of focus group discussions.

Results: Forty peri- and postmenopausal women were recruited through hospital fliers $(n=25)$ and a community health fair $(n=15)$. Mean age was 51 years, $50 \%$ were non-Caucasian, and all had completed high school. Bar graphs were preferred by $83 \%$ of participants over line graphs, thermometer graphs, 100 representative faces, and survival curves. Lifetime risk estimates were preferred over 10 or 20-year horizons, and absolute risks were preferred over relative risks and number needed to treat.

Conclusion: Athough there are many different formats for presenting and framing risk information, simple bar charts depicting absolute lifetime risk were rated and ranked highest overall for patient preferences for format. 


\section{Background}

With the rising trend towards consumerism in health, patients are increasingly encouraged to become involved in making decisions about their health. Marketing campaigns for prescription drugs are now being directed towards patients, with advertisements appearing in the popular press suggesting that patients discuss medications and treatment options with their doctors. A recent study examining the effect of drug advertisements on consumer behavior found that $19 \%$ of study participants asked for a prescription, and $35 \%$ asked a physician for information about a drug after seeing a drug advertisement [1]. In order for patients to be effective participants in the decision making process, they need information on the effects of treatment on their health risks that they can use to make health care decisions. The challenge to clinicians is how to present risk information to patients that they can use in a format that they prefer.

Several studies have examined how presentation, [2-4] wording, [5] and framing [6,7] affect physicians' interpretations of numeric data as well as their willingness to initiate treatment [8]. However, few studies have examined the effect on patients of framing risk data with different metrics, such as relative or absolute risk and the number needed to treat (NNT). Relative risk describes the ratio of the risk of disease in one group compared to that in another and does not take into consideration a person's baseline risk. Absolute risk describes the difference between the risks of disease in two populations and varies according to baseline risk. A derivative of absolute risk is the NNT with a specific therapy to prevent one adverse outcome (the inverse of the difference in absolute risk). Framing the benefits of treatment in relative rather than absolute terms may emphasize the short-term benefits of a treatment $[6,9]$. Conversely, framing the risks of treatment in relative rather than absolute terms may emphasize its risks [10]. Comparing relative and absolute risk reduction and NNT as methods to inform patients about preventive therapies, Hux et al illustrated that the metric used to present data can affect a patient's perception of a therapy's effectiveness [11].

In addition to consideration of which metric is used to describe risks, the time horizon over which risks or benefits occur may affect risk interpretation. Typically, risks framed in relative terms are not explicit about the time frame involved and may be erroneously interpreted as accruing immediately. On the other hand, risks framed in absolute terms or as the NNT tend to report a specific time frame and hence may be interpreted as being delayed in onset. In addition to issues related to comprehension, patients may prefer to have risks presented over specific time periods.
While most framing studies focused on a treatment's effect on a single outcome over a single time horizon, patients often need to decide on treatments that affect multiple outcomes, both beneficial and harmful. For example, the decision of whether or not to use hormone replacement therapy (HRT) after menopause involves weighing the benefits of treatment (immediate symptom relief, [12] decreased future risk of hip fracture [13] and possible decreased risk of coronary heart disease [14,15]) against its risks (increased future risk of breast cancer [15]). Framing effects appear to be smaller when both the beneficial and harmful effects of a treatment are included, [16] but little information is available to guide clinicians about how to explain complex risk information to their patients.

Most studies exploring risk communication and decision-making have focused on the use of different metrics. However, data can be described using a variety of different graphical formats as well. Survival curves are commonly used in the scientific literature and can also be used to help patients understand risk information when deciding between two treatments [2]. Figures using 100 faces or ovals to represent populations with and without a condition, displayed in a random [17] or consolidated [18] fashion, have gained increasing popularity in the lay press, as have simple bar charts.

The choice of graphical formats may affect patient performance on cognitive tests, [19-23] accuracy of comprehension, and speed of processing probabilistic information. Vertical bars, horizontal bars, numbers, and 100 consolidated ovals performed better than either pie charts or 100 random ovals when testing simplified cognitive tasks (e.g., identifying the larger of two quantities) [24]. The type of visual graphic used to present information can also introduce bias in risk perception, with risk perceived to be less when using a bar graph versus a stick figure [25].

Numerous criteria have been used to evaluate graphical formats, including clarity, helpfulness,[26,27] accuracy and efficiency, [24] though these criteria may not necessarily be those of greatest importance to patients themselves. Although it is unclear which criteria should be used to evaluate formats to use with patients, patient preferences may be an important consideration. Formats preferred by patients may reflect higher perceived relevance, familiarity, usefulness, usability, and meaningfulness, and hence may be more successful in engaging their attention. The aim of this study is to determine patient preferences for the presentation of complex benefit/risk information describing the impact of treatment on multiple clinical outcomes over multiple time horizons, including preferences for graphic format,time hori- 
zons, multiple outcomes comparisons, and metrics. The specific example tested was deciding on HRT among a population of peri-and postmenopausal women.

\section{Methods}

Peri- and postmenopausal women were recruited for participation through hospital fliers and advertisements. Focus groups were convened to discuss decision-making issues about HRT as well as patient preference for risk presentation. Recruitment ceased when convergence was reached on the broader topics addressed. Of the 37 women who responded to fliers and ads, 25 participated in 8 focus group sessions held at New England Medical Center from March through May 1999. No information was obtained on women who did not attend a focus group. Each 2-hour session was conducted by 2 facilitators (NFC, LKH) and was audio taped. All tapes were transcribed and reviewed for subjective evaluation. Because most of the focus group participants were Caucasian, 15 non-Caucasian women were recruited to participate in one-on-one interviews through a community health fair.

All participants were asked to evaluate different ways of communicating risk estimates for coronary heart disease, hip fracture, and breast cancer, both with and without HRT. All risk estimates were derived from a Markov model [28] that used individual risk factors to predict future disease risk. Risk estimates were based on a hypothetical 50-year old woman's risk factor profile and were displayed over 10-year, 20-year and lifetime horizons. All graphical presentations depicted identical numerical risk levels, differing only in the metrics and formats used. To avoid "group think" resulting from focus group discussions, participants were asked to privately record their preferences on a worksheet before the group discussion convened. These worksheets were collected after the discussions and data were extracted and analyzed. Specific reasons for participants' preferences were elicited using open-ended questions.

\section{Graphic format}

We identified the following graphic formats as being the most commonly used in the scientific and popular press, and therefore the most recognizable to patients: bar graphs, line graphs, thermometer graphs, 100 representative faces displayed in a consolidated fashion, and survival curves (Figures 1, 2). The survival curve was atypical in that its $y$-axis presented a patient's chance of not developing a disease instead of the more standard "chance of survival". This modification was made to keep the data presented consistent with data presented in the other graphical formats since survival was not presented in the other graphs (the chance of not developing a disease is the closest equivalent to survival, which is the chance of not dying). Pie charts were not included because this format did not readily lend itself to describing risks over time. Participants were sequentially presented with all graphic formats and each was briefly explained. Participants were asked to rate how much they liked each graph on a likert scale of 1 to 5 , with 1 corresponding to "not at all" and 5 corresponding to "extremely", and then to rank order the graphs according to preference.

\section{Time horizons}

Participants were also asked to rank order their preferences for risk estimates over 10-year, 20-year, or lifetime horizons, presented using bar graphs predicting a woman's risk for developing heart disease, hip fracture and breast cancer.

\section{Multiple Outcomes}

Participants' preferences for risk displays about multiple clinical outcomes were elicited by asking participants to choose between 2 sets of 3 graphs. In Set A, each of three diseases was displayed separately over 3 time horizons (Figure 3). In Set B, the same three diseases were displayed together over one time horizon; this was repeated for the other two time horizons (Figure 4). Note that the exact same data were presented in each set, differing only in format.

\section{Metrics}

Preferences for absolute vs. relative risk estimates were obtained by asking participants to choose between risk estimates for heart disease framed in either absolute or relative terms, both graphically and textually. Finally, participants evaluated the concept of NNT presented with two written explanations. The first explanation (referred to as " 1 in $x^{\text {") }}$ was worded "If 8 women just like you took lifelong HRT, it would prevent one of the 8 from having heart disease. If 9 women took lifelong HRT, it would prevent one of the 9 from having a hip fracture. If 17 women took lifelong HRT, it would cause one of the 17 to develop breast cancer. There is no way of knowing in advance who these women might be." The alternative explanation (referred to as "x out of 100") was worded "If 100 women just like you were to take lifelong HRT, treatment would prevent 12 of them from developing heart disease and 11 of them from developing a hip fracture. However, treatment would cause 6 of them to develop breast cancer. There is no way of knowing in advance who these women might be."

We assessed differences in patients' preferences between the two graphs with the highest mean rating using a Wilcoxon signed-rank test. Descriptive statistics were performed on subgroups stratified according to race (Caucasian vs. non-Caucasian), annual household income $(<\$ 50,000$ vs. $\geq \$ 50,000)$, and education $(<2$ years 
college vs. $\geq 2$ years college). Statistical comparisons within subgroups were not performed due to the small sample size.

\section{Results}

Study participants included a diverse group of 40 periand post-menopausal women (Table 1). Half of our sample identified themselves as non-Caucasian. All participants had at least some high school education; most (60\%) had an annual household income of less than $\$ 50,000$.

Table I: Demographic Characteristics of Sample Population

\begin{tabular}{|c|c|}
\hline Sample size & 40 women \\
\hline Mean age, yrs (range) & $51(38-67)$ \\
\hline \multicolumn{2}{|l|}{ Age group, yrs } \\
\hline$<45$ & 6 \\
\hline $45-55$ & 24 \\
\hline$>55$ & 10 \\
\hline \multicolumn{2}{|l|}{ Race } \\
\hline Non-Caucasian & 20 \\
\hline Caucasian/Non-Hispanic White & 20 \\
\hline \multicolumn{2}{|l|}{ Annual Household Income } \\
\hline Less than $\$ 25,000$ & 11 \\
\hline$\$ 25,000-\$ 49,999$ & 13 \\
\hline$\$ 50,000-\$ 74,999$ & 5 \\
\hline$\$ 75,000-\$ 99,999$ & 5 \\
\hline$\$ 100,000$ or more & 6 \\
\hline \multicolumn{2}{|c|}{ Highest Level of Education Completed } \\
\hline Grade 9-12 & 6 \\
\hline Technical/Vocational & 3 \\
\hline 2 years of college & 12 \\
\hline 4 years of college & 9 \\
\hline Post-graduate degree & 10 \\
\hline
\end{tabular}

The mean preference rating for the bar graph exceeded those of the four other graphs in this set (Table 2). Most respondents (83\%) ranked the bar graph as being their first or second most preferred graph, with more than half of all respondents (60\%) selecting the bar graph as their first choice (Figure 5). The bar graph was consistently rated highest when the sample population was stratified according to race, income and educational status. Subgroup analyses are shown in Table 2, recognizing that these analyses are limited considering the small sample size.

Most respondents preferred receiving risk estimates over multiple time horizons vs. at one time point. When asked to prioritize, a majority preferred receiving lifetime risk estimates instead of 10 or 20-year time horizons (Table 3a). There was no clear preference for the type of presentation comparing risks for multiple disease outcomes over different time horizons (Table 3b). Respondents preferred risk estimates framed in absolute rather than relative terms for both graphical and textual displays (Table 3c); this finding was consistent across racial, income, and educational sub-groups. Participants consistently stated that they wanted graphical and textual explanations of absolute risks provided together. In describing NNT, respondents preferred the written explanation which rescaled data from "1-in x" to "x out of 100" (Table 3d).

Table 2: Mean Preference Ratings of Graphical Displays of Risk Information (SD)

\begin{tabular}{|c|c|c|c|c|c|c|c|c|}
\hline & Display $^{\dagger}$ & $\begin{array}{l}\text { Overall } \\
(n=40)\end{array}$ & $\begin{array}{l}\text { Non-Caucasian } \\
\quad(n=20)\end{array}$ & $\begin{array}{c}\text { Caucasian } \\
(n=20)\end{array}$ & $\begin{array}{l}\text { Lower income } \\
\qquad(\mathrm{n}=24)\end{array}$ & $\begin{array}{l}\text { Higher income } \\
\qquad(\mathrm{n}=16)\end{array}$ & $\begin{array}{l}\text { Lower education } \\
\qquad(\mathrm{n}=9)\end{array}$ & $\begin{array}{l}\text { Higher education } \\
\qquad(\mathrm{n}=3 \mathrm{I})\end{array}$ \\
\hline I. & Bar graph & $4.0 \neq(1.0)$ & $3.5(1.1)$ & $4.4(0.7)$ & $4.0(1.0)$ & $3.9(1.0)$ & $3.4(1.2)$ & $4.1(0.9)$ \\
\hline 2. & Line graph & $3.1(0.9)$ & $3.2(0.9)$ & $3.0(0.9)$ & $3.0(1.0)$ & $3.2(0.8)$ & $2.9(1.1)$ & $3.1(0.9)$ \\
\hline 3. & $\begin{array}{l}\text { Thermometer } \\
\text { graph }\end{array}$ & $2.6(I .1)$ & $2.7(1.0)$ & $2.5(1.1)$ & $2.6(1.1)$ & $2.6(1.1)$ & $2.4(0.9)$ & $2.7(1.1)$ \\
\hline 4. & 100 faces & $2.4(1.5)$ & $2.6(1.5)$ & $2.2(1.5)$ & $2.8(1.5)$ & $1.8(1.3)$ & $3.3(1.1)$ & $2.1(1.5)$ \\
\hline 5. & Survival curves $\S$ & $2.5(I . I)$ & $2.3(1.1)$ & $2.9(1.0)$ & $2.6(1.2)$ & $2.4(0.9)$ & $2.6(1.1)$ & $2.5(1.1)$ \\
\hline
\end{tabular}

†Lower income reflects annual household income below $\$ 49,999$; higher income reflects annual household income above $\$ 50,000$. Lower education reflects completion of grades 9-12 or Technical/Vocational school. Higher education reflects 2 or 4 years of college or a post-graduate degree. ${ }^{\ddagger}$ Wilcoxon signed rank test for difference between bar and line graph ratings $(\mathrm{p}<0.001)$. ${ }^{\S}$ Presented to 35 participants $(20$ non-Caucasian, 15 Caucasians; 22 lower income, 13 higher income; 7 lower education, 28 higher education). Percentages reflect appropriate adjustments. 
Table 3: Preferences for Risk Information Presentations

\begin{tabular}{|c|c|c|}
\hline a. Time Horizon & $\begin{array}{c}\text { I }^{\text {st }} \text { Choice } \\
(n=40)\end{array}$ & $\begin{array}{c}2^{\text {nd }} \text { Choice } \\
(n=33)\end{array}$ \\
\hline 10-year & $23 \%$ & $12 \%$ \\
\hline 20-year & $20 \%$ & $58 \%$ \\
\hline Lifetime & $55 \%$ & $27 \%$ \\
\hline No response & $3 \%$ & $3 \%$ \\
\hline b. Multiple diseases, multiple time & Preference & \\
\hline horizons & $(n=40)$ & \\
\hline Set A: I disease over 3 time horizons & $53 \%$ & \\
\hline Set B: 3 diseases over I time horizon & $43 \%$ & \\
\hline No response & $5 \%$ & \\
\hline \multirow[t]{2}{*}{ c. Relative vs. absolute risk } & Graph & $\begin{array}{c}\text { Text Pre- } \\
\text { ference }\end{array}$ \\
\hline & $\begin{array}{l}\text { Preference } \\
\quad(n=25)\end{array}$ & $(n=20)$ \\
\hline Relative risk & $28 \%$ & $30 \%$ \\
\hline Absolute risk & $72 \%$ & $65 \%$ \\
\hline No response & $0 \%$ & $5 \%$ \\
\hline \multirow[t]{2}{*}{ d. NNT } & Preference & \\
\hline & $(n=40)$ & \\
\hline Standard explanation ( $I$ in $x)$ & $28 \%$ & \\
\hline Alternative explanation (x out of 100 ) & $45 \%$ & \\
\hline Neither & $25 \%$ & \\
\hline No response & $3 \%$ & \\
\hline
\end{tabular}

*Percentages may not total $100 \%$ due to rounding.

\section{Discussion}

Whereas no single format for communicating risk estimates was favored by all respondents, the majority of our sample population preferred a bar graph over a line graph, a thermometer graph, 100 faces, and a survival curve. Focus group participants remarked that the bar graph was "real basic" and "simplistic, I could deal with that". Respondents also commented that this graph type "shows the information clearer" than other graph choices. We could not exclude the possibility that participants preferred formats that were more familiar to them, but no one explicitly reported that as being a consideration.

There was a smaller difference in mean preference rating among non-Caucasian than among Caucasian respondents. It is possible that this was due to the fact that these discussions were conducted 1-on-1 as opposed to focus group discussions. However, this is not likely as the 1-on1 discussions were time-constrained and highly focused.
The largest difference in graph preferences amongst the sub-groups was the tendency of women who were nonCaucasian, of lower income, or of lower educational status to give the 100 faces figure a higher ranking than did women who were Caucasian, had higher incomes, or higher educational levels. However, this finding was based on limited sub-group analyses. Whereas some participants saw the 100 faces as being "more exact...there's actual happy faces you can count", others remarked that it was "too much, too busy" and "simple".

The majority of our participants indicated that they would like to have their risk estimates presented over all three time horizons. Arguments for having all three time horizons included "obviously I want a healthy lifetime, but whatever I do to fight these diseases, if I fight them within the next ten years, that's going to stand me in good stead for the rest of my life". However, when asked to prioritize which single time horizon they preferred, more than half preferred a lifetime estimate, with one respondent commenting "I chose lifetime. I like to see it all". This finding is consistent with those of Mazur et al. who found that patients were more influenced by the end-points of survival curves rather than the area or shape of the survival curve. [2] This may denote a preference for risk data to be presented as a lifetime estimate instead of as points in time along an axis. Although physicians tend to report risks using intermediate data (such as 5-year survival estimates) when recommending treatments, [4] patients may be more interested in long-term benefits and risks.

There was no clear consensus about whether graphs should display one disease outcome over many time horizons or many disease outcomes for one time horizon, even though slightly more respondents favored the latter. Respondents who wanted to see risk information as three disease outcomes over one time horizon per graph argued that they liked everything "all on one sheet", and that "I might get breast cancer, but I wouldn't get this or I wouldn't get that...sometimes it comes to a trade-off." Arguments for presenting one disease outcome at a time over many time horizons included "I would want to look at my results...specifically just my osteoporosis risk...and this is my heart disease and this is my cancer." Small sample size limited the ability to explore whether a woman's concern for a single (vs. multiple) disease predicted her presentation preferences.

Also consistent with recent research, respondents preferred data framed in absolute rather than relative terms. Whereas physicians may find relative risk estimates to be valuable in deciding whether to recommend a treatment, [29] framing data as absolute risk may be more informative and help patients who are making decisions about 


\section{Bar graph}

Your Chance of Dereloping Coronary Heart Disease

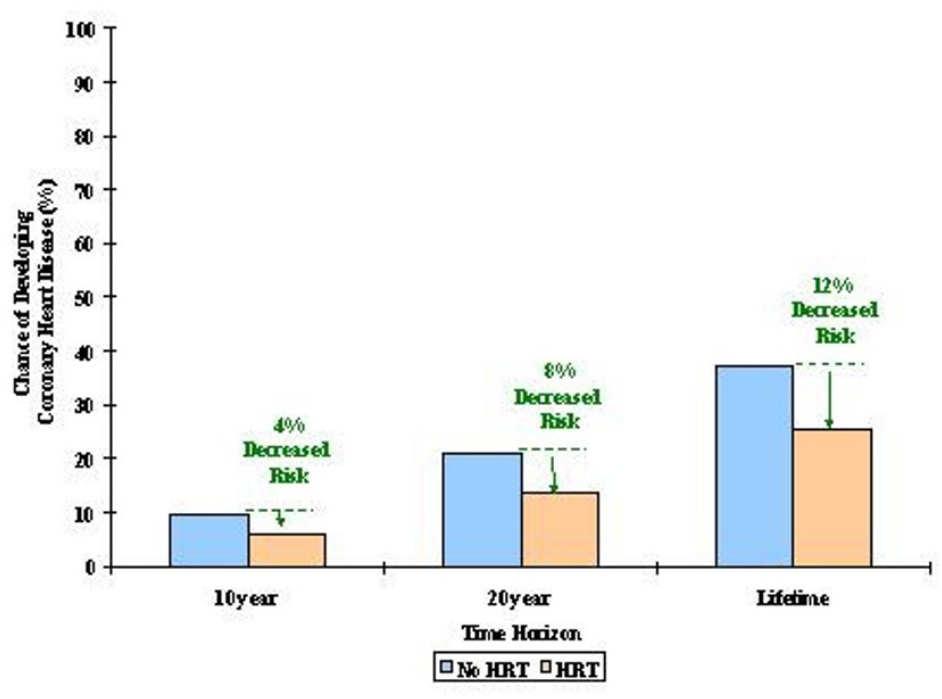

\section{Line graph}

Your Chance of Develop ing Coronary Heart Disease

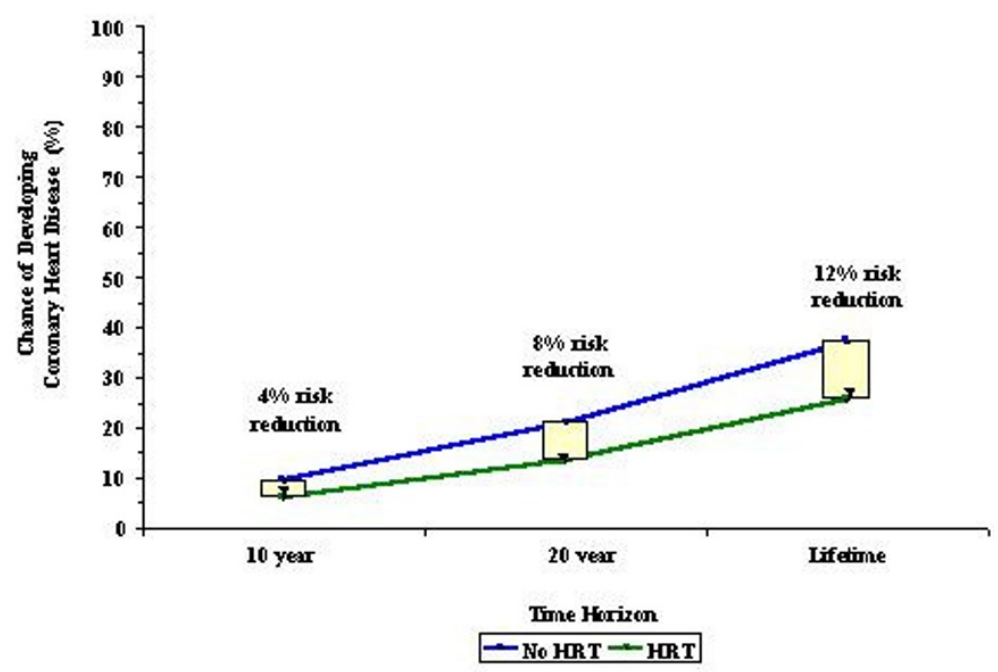

Figure I

Graphical Displays of Risk Estimates: Bar Graph and Line Graph 


\section{Thermometer graph}

Your Chanc ef Developing Coranary Heart nisease

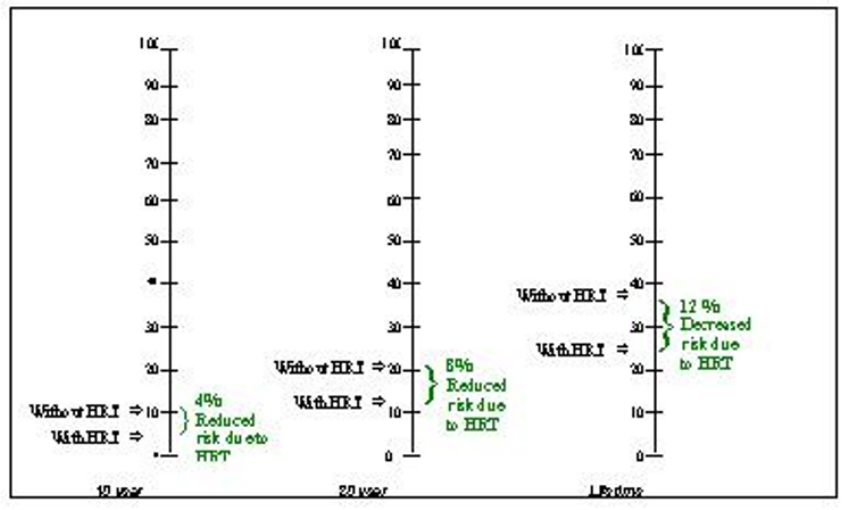

\section{100 faces}

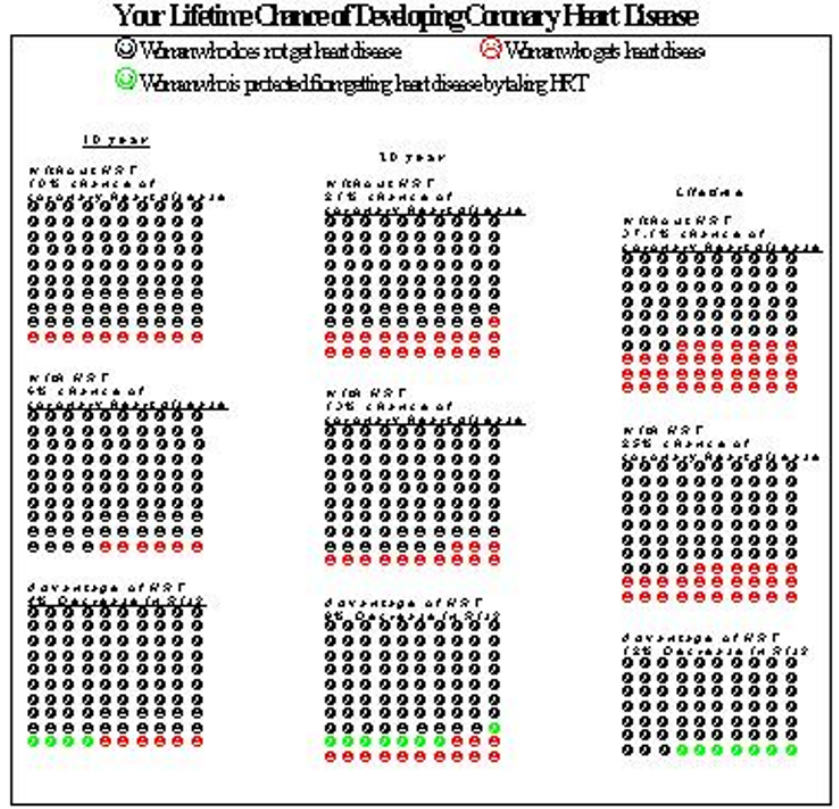

\section{Survival curves}

Your Chance of W ot Developing Heart Disease

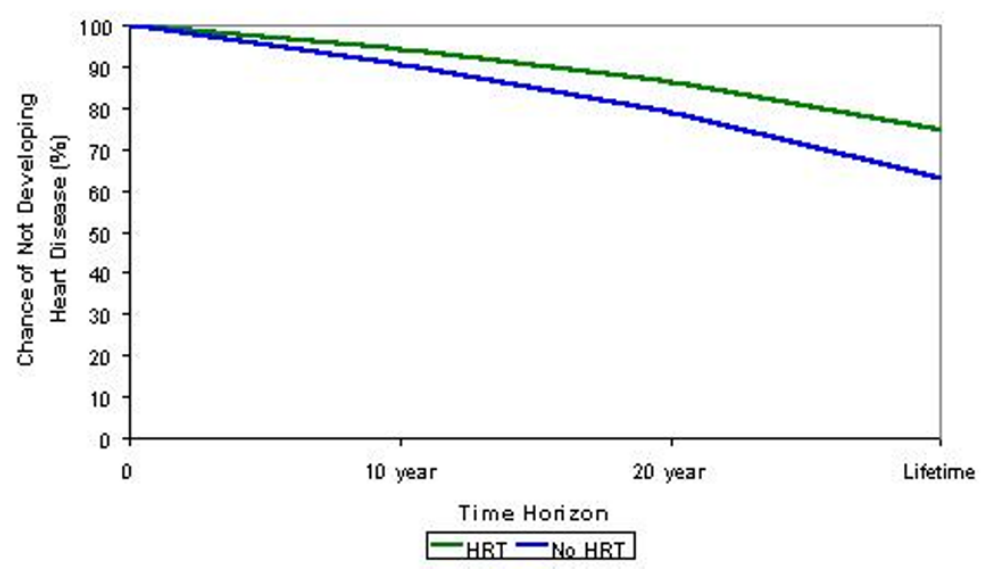

Figure 2

Graphical Displays of Risk Estimates: Thermometer Graph, 100 Faces, and Survival Curves 
1. Your Chance of Developing C oronaryHeart Disease

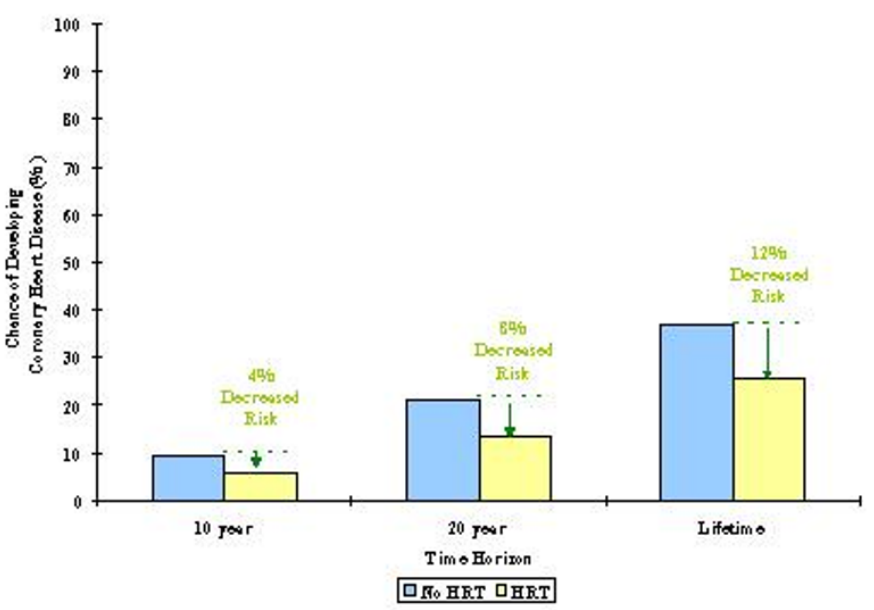

2.

Your Chance of Desebpinga fip Fracture

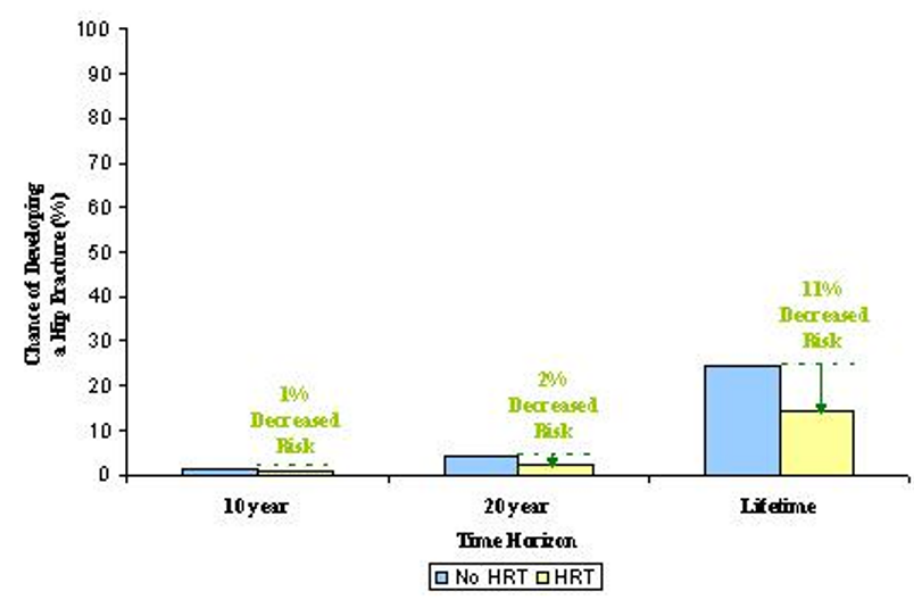

3.

Your chance of Developing Breast $c$ ancer

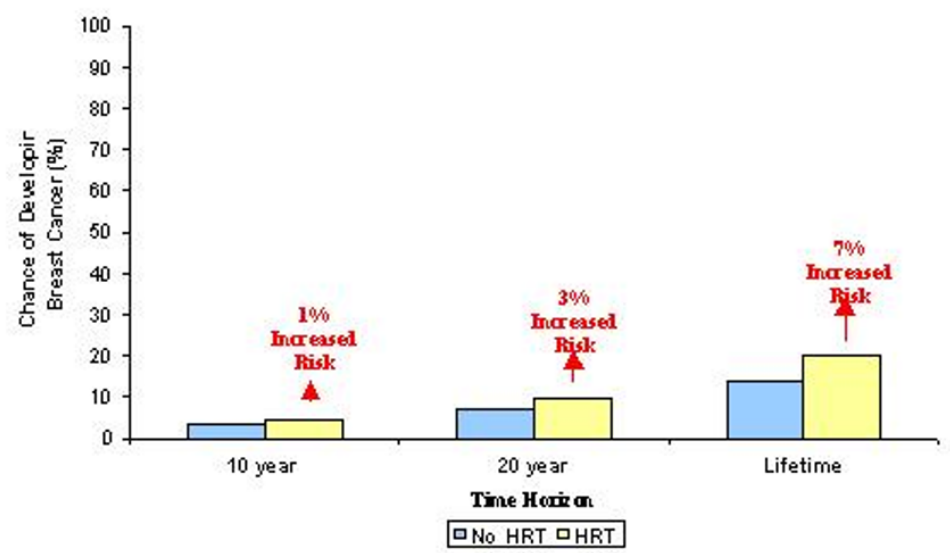

Figure 3

Risk Displays on Multiple Disease Outcomes Over Different Time Horizons, Set A: Each graph shows the risk for one disease over multiple time horizons with and without HRT (I. Coronary Heart Disease, 2. Hip Fracture, 3. Breast Cancer). 
4.

Your 10 Year chance of Developing

Coronary Heart Disease, HP Fracture, and Breast Cance

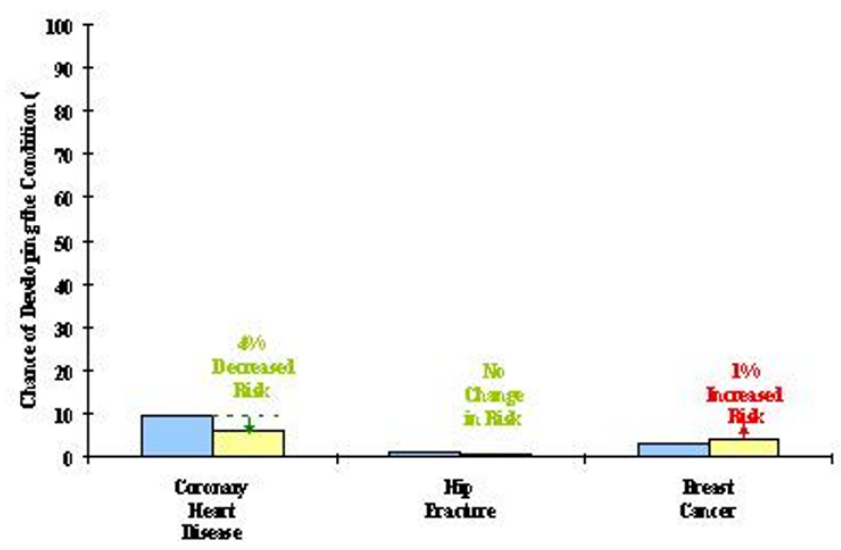

口No HRT पYWinHRT

5.

Y orr 20 Year chance of Developing

Cormary Heart Disease, fin Frature, and Breast $C$ ance

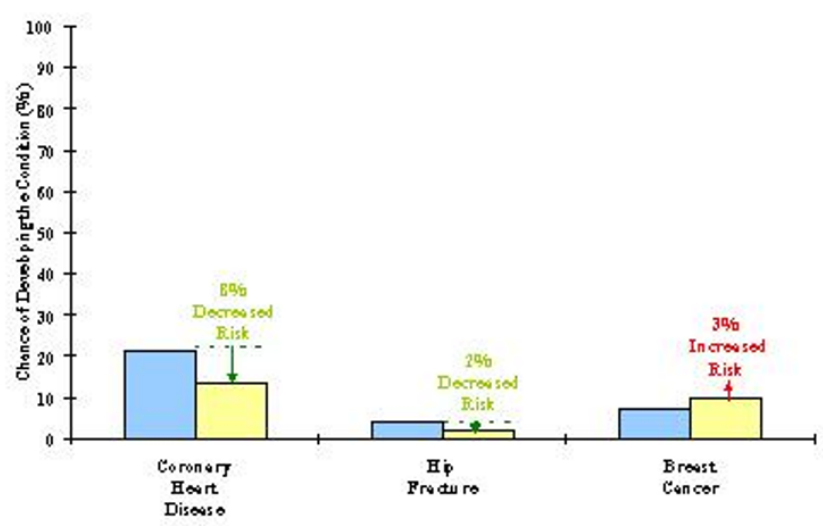

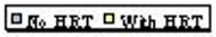

6.

Your Liffetine Chance of Developing Cormary Heart Disease, Hị Frature, and Breast Cance

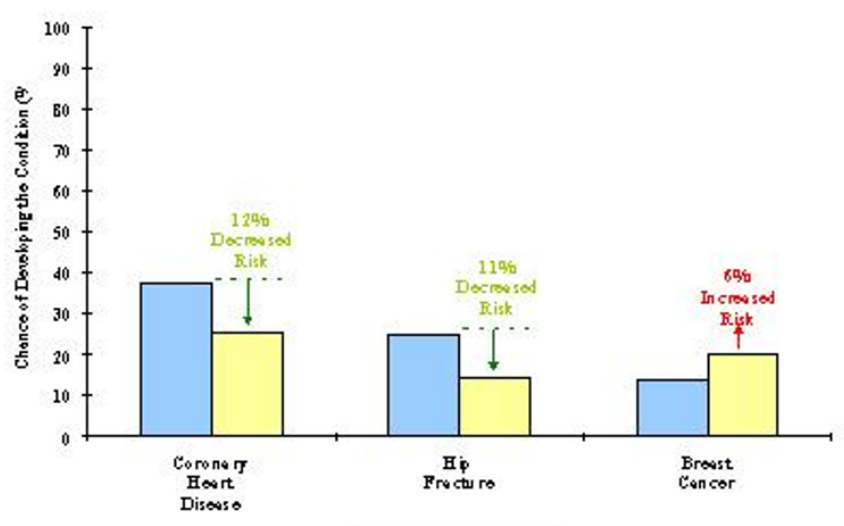

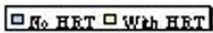

Figure 4

Risk Displays on Multiple Disease Outcomes Over Different Time Horizons, Set B: Each graph shows the risk for three diseases over one time horizon with and without HRT (4. Ten-year estimates, 5. Twenty-year estimates, 6. Lifetime estimates). 


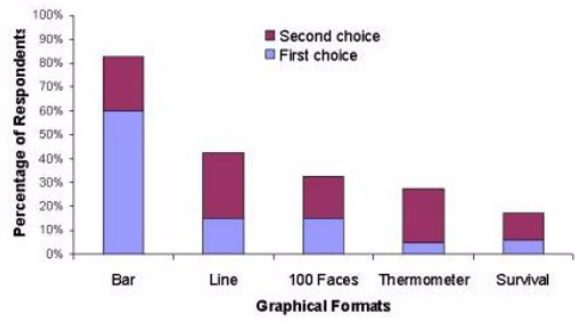

Figure 5

Ranking of Graphical Formats Containing Risk Information

treatment options [29]. Focus group participants remarked that the graph presenting relative risk was "too alarming because the risks appeared bigger". Also, one respondent commented that she would "just want to know that the example is $100 \%$," referring to the absolute risk graph presented on a 100\% scale as opposed to the 40\% scale used in the relative risk graph.

Few respondents preferred their risk estimates to be presented as NNT. Although this concept may be useful to physicians because it accounts for differences in baseline risks, [30] it did not find favor among our study participants who remarked that the concept was "confusing" and often asked focus group leaders for clarification. This finding is consistent with results by Cook et al who found that explaining risk estimates in terms of NNT during patient rounds can be time consuming and subject to patient misinterpretation [31].

\section{Limitations}

The present study included a small, self-selected population of women who were more likely to be interested in health-related activities. Our sample size was small because focus groups and 1-on-1 interviews were originally conducted to discuss HRT and decision-making issues. When convergence was reached on these broader topics, we ceased recruitment and analyzed data from these respondents. While these results may not be generalizable to all women, our sample included a diverse group of women with respect to race, income, and educational background. Recognizing that focus group discussions might lead to "group think", we control for this by asking participants to privately write down their personal preferences before they were discussed.
A formal analysis of patient comprehension for each presentation format was beyond the scope of the present study; however data on this topic has been previously reported [24]. While responses from focus group participants reflected how well they felt they could understand the information in various formats, no formal testing of comprehension was performed. Analyzing comprehension of each format at this stage was not feasible considering the additional time burden it would have imposed on our study participants (focus group sessions lasted a full 2 hours). Presentation formats that are not understandable may be misinterpreted; formats that are unappealing may be ignored. Therefore, future studies might test both comprehension and patient preferences simultaneously to develop future risk communication tools.

The graphical presentations utilized were hypothetical in that they did not present each individual's personal risk estimates, but those of a theoretical woman. It is unlikely that patients' preferences for risk estimate presentations would have been different had they been shown their own risk estimates. Not all possible graph types were presented to study participants, although we attempted to include the most common graph types from the scientific and popular press. Although we did not systematically study the reasons for participants' stated preferences, participants were asked open-ended questions to understand these preferences. Finally, since scientific literature traditionally presents 5-year survival data, it might be difficult to compare our data, based on 10-year, 20-year and lifetime horizons, to that in the current literature.

\section{Conclusions}

Patients preferred health risks to be framed in absolute terms, using bar graphs, and calculated over their expected lifetime. There was no clear preference for presenting a treatment's effect on multiple outcomes. The NNT is not an easily understood concept for patients, but if used to discuss multiple outcomes, it should be rescaled to "x out of 100". The results of these analyses should help physicians present risk/benefit information to patients in a clear and useful manner.

\section{Competing interests}

None.

\section{References}

I. Bell RA, Kravitz RL, Wilkes MS: Direct-to-consumer prescription drug advertising and the public. JGIM 1999, |4:65|-657

2. Mazur DH, Hickam DH: Interpretation of graphic data by patients in a general medicine clinic. JGIM 1990, 5:402-405

3. Mazur DJ, Merz JF: How the manner of presentation of data influences older patients in determining their treatment preferences. JAGS 1993, 41:223-228

4. Mazur DJ, Hickam DH: Patients' and physicians' interpretations of graphic data displays. Med Decis Mak 1993, I3:59-63 
5. Woloshin S, Schwartz LM, Black WC, Welch HG: Women's perceptions of breast cancer risk: How you ask matters. Med Decis Mak 1999, 19:221-229

6. Malenka DJ, Baron JA, Johansen S, Wahrenberger JW, Ross JM: The framing effect of relative and absolute risk. JGIM 1993, 8:543548

7. McGettigan P, Sly K, O'Connell D, Hill S, Henry D: The effects of information framing on the practices of physicians. JGIM 1999 , I 4:633-642

8. Hux JE, Levinton CM, Naylor CD: Prescribing propensity: Influence of life-expectancy gains and drug costs. JGIM 1994, 9:19520I

9. Forrow L, Taylor WC, Arnold RM: Absolutely relative: How research results are summarized can affect treatment decisions. Amer J Med 1992, 92:121-124

10. Bucher HC, Weinbacher M, Gyr K: Influence of method of reporting study results on decision of physicians to prescribe drugs to lower cholesterol concentration. BMJ 1994, 309:76I764

II. Hux JE, Naylor CD: Communicating the benefits of chronic preventive therapy: Does the format of efficacy data determine patients' acceptance of treatment? Med Decis Mak 1995, I 5:152-157

12. Barrett-Connor E: Hormone replacement therapy. BMJ 1998, 3|7:457-46|

13. Grady D, Rubin SM, Petitti DB, Fox CS, Black D, Ettinger B, et al: Hormone therapy to prevent disease and prolong life in postmenopausal women. Ann Intern Med 1992, II 7:1016-1037

14. Hulley S, Grady D, Bush T, Furberg C, Henington D, Riggs B, Vittinghoff $E$ : Randomized trial of estrogen plus progestin for secondary prevention of coronary heart disease in postmenopausal women. JAMA. 1998, 280:605-6I3

15. Colditz GA, Hankinson SE, Hunter DJ, Willett WC, Manson JE, Stampfer MJ, Hennekens C, Rosner B, Speizer FE: The use of estrogens and progestins and the risk of breast cancer in postmenopausal women. N Engl J Med 1995, 332:I 589- 1593

16. Nikolajevic-Sarunac J, Henry DA, O'Connell DL, Robertson J: Effects of information framing on the intentions of family physicians to prescribe long-term hormone replacement therapy. JGIM 1999, 14:591-598

17. O'Connor AM, Tugwell P, Wells GA, Elmslie T, Jolly E, Hollingworth $G$, al et: A decision aid for women considering hormone therapy after menopause: Decision support framework and evaluation. Patient Educ Counsel. 1998, 33:267-279

18. Lenert LA, Cher D: Use of meta-analytic models to support shared decision making over the WWW. JAMIA. 1999, 6:412419

19. Dickson GW, DeSanctis G, McBride DJ: Understanding the effectiveness of computer graphics for decision support: a cumulative experimental approach. Communications of the ACM. 1986, 29:40-7

20. Lucas HC, Nielson NR: The impact of the mode of information presentation on learning and performance. Manage Sci. 1980, 26:982-93

21. Bradt B: Informational needs and selected variables in patients receiving brachytherapy. Oncol Nurs Forum. 1991, 18:12217

22. Powers M, Lashley C, Sanchez P, Shneiderman B: An experimental comparison of tabular and graphic data presentation. Int J Man-Machine Studies. 1984, 20:545-66

23. Tullis TS: An evaluation of alphanumeric, graphic and color information displays. Human Factors. 198I, 23:53I-50

24. Feldman-Stewart D, Kocovski N, McConnell BA, Brundage MD, Mackillop W]: Perception of quantitative information for treatment decisions. Med Decis Making. 2000, 20:228-238

25. Schapira M, Nattinger A, Eparvier : Identification of a risk magnitude bias associated with type of graphic format used to present probabilistic information. Med Decis Making. 2000

26. Lipkus IM, Hollands JG: The visual communications of risk. $J \mathrm{NCI}$ Monographs. 1999, 25:149-163

27. Weinstein ND, Sahdman PM: Some criteria for evaluating risk Risk Anal. 1993, 13:103-114

28. Col NF, Eckman MH, Karas RH, Pauker SG, Goldberg RJ, Ross EM, Orr RK, Wong JB: Patient-specific decisions about hormone replacement therapy in postmenopausal women. JAMA 1997. 277:1140-1147
29. Dupont WD, Plummer WD: Understanding the relationship between relative and absolute risk. Cancer 1996, 77:2193-2199

30. Chatellier G, Zapletal E, Lemaitre D, Menard J, Degoulet P: The number needed to treat: a clinically useful monogram in its proper context. BMJ 1996, 3 I2:426-429

31. Cook RJ, Sackett DL: The number needed to treat: a clinically useful measure of treatment effect. BM] I995, 3 I 0:452-4

\section{Pre-publication history}

The pre-publication history for this paper can be accessed here:

http://www.biomedcentral.com/content/backmatter/

1472-6947-1-2-b1.pdf

Publish with BioMed Central and every scientist can read your work free of charge

"BioMedcentral will be the most significant development for disseminating the results of biomedical research in our lifetime."

Paul Nurse, Director-General, Imperial Cancer Research Fund

Publish with BMC and your research papers will be:

- available free of charge to the entire biomedical community

- peer reviewed and published immediately upon acceptance

- cited in PubMed and archived on PubMed Central

- yours - you keep the copyright 